\title{
Charles De Montalembert, Journal intime inédit
}

\section{Catherine Gaviglio-Faivre D'arcier}

\section{(Q) OpenEdition}

\section{Journals}

\section{Édition électronique}

URL : http://journals.openedition.org/studifrancesi/36492

DOI : 10.4000/studifrancesi.36492

ISSN : 2427-5856

Éditeur

Rosenberg \& Sellier

\section{Édition imprimée}

Date de publication : 1 juillet 2005

Pagination : 189

ISSN : 0039-2944

\section{Référence électronique}

Catherine Gaviglio-Faivre D'arcier, «Charles De Montalembert, Journal intime inédit », Studi Francesi [En ligne], 145 (XLIX | I) | 2005, mis en ligne le 30 novembre 2015, consulté le 18 avril 2021. URL : http:// journals.openedition.org/studifrancesi/36492 ; DOI : https://doi.org/10.4000/studifrancesi.36492

\section{Ce document a été généré automatiquement le 18 avril 2021.}

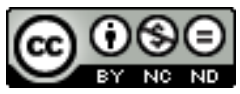

Studi Francesi è distribuita con Licenza Creative Commons Attribuzione - Non commerciale - Non opere derivate 4.0 Internazionale. 


\title{
Charles De Montalembert, Journal intime inédit
}

\author{
Catherine Gaviglio-Faivre D'arcier
}

\section{RÉFÉRENCE}

CHARLES DE MONTALEMBERT, Journal intime inédit, t. III (1834-1843), texte présenté, établi et annoté par LOUIS LE GULLLOU et NICOLE ROGER-TAILLADE, Paris, Honoré Champion, 2003, pp. 595.

1 Les deux précédents volumes du Journal de Montalembert, publiés il y a plus de dix ans, s'arrêtaient sur la situation désespérée de leur auteur. Après la mort de son père, survenaient la mort de sa sœur, puis les encycliques condamnant Lamennais, en qui il avait placé bien des espoirs, enfin l'échec de son mariage avec la princesse polonaise Edwige Lubomirska.

2 Le troisième tome, qui couvre une dizaine d'années, se révèle extrêmement riche, en particulier sur les plans affectif et politique. On y voit un Montalembert, vexé, entreprendre de grands voyages en Italie, Suisse et Allemagne, pour tenter d'oublier la blessure causée par le refus d'Edwige. Avec une sensibilité très romantique, il exhale dans les pages de son journal sa colère, sa douleur, son amertume. Il tente de trouver un peu de consolation dans un travail consacré à Sainte-Élisabeth, mais se plaît surtout à remarquer souvent des correspondances entre ses tristes états d'âme et les paysages montagneux qu'il traverse. Son retour en France, début 1835, est peu joyeux. Il perd un de ses très chers amis, se fait du souci pour son frère, retourne dans le grand monde parisien et à la chambre des pairs sans grand enthousiasme. Il lui faut attendre 1836 pour trouver enfin un grand apaisement, grâce à son mariage avec la toute jeune Anne de Mérode, issue de la grande noblesse belge et fervente catholique, comme lui. Les préparatifs de leur union, dignes d'une Carte du Tendre, inaugurent une vie nouvelle pour Montalembert. Amoureux fou de sa femme, il parcourt avec elle l'Italie pour 
effacer dans son cœur le souvenir d'Edwige et sceller son retour définitif dans le giron de l'Église par une double réception papale.

3 Le bonheur familial goûté auprès de son «Angesse», même troublé par le décès de deux de leurs quatre filles, lui donne plus d'assurance. Il s'élance sur la scène politique, où ses discours à la chambre des pairs, même improvisés, lui assurent de beaux succès; il tente d'imposer le général Skrzynecki à la tête de l'armée belge et influe sur la nomination de certains évêques.

4 Parallèlement à sa carrière politique qui, malgré tout, ne le satisfait pas pleinement, Montalembert voyage beaucoup (seul ou accompagné par son beau-père ou des amis) pour marcher sur les traces de Saint Bernard ou pour trouver un château où s' établir, en particulier en Bretagne. Ses récits, édifiants sur les conditions de voyage de l'époque, charmants par le pittoresque de la narration - Montalembert s'insurge, entre autres, contre le vandalisme auquel sont soumis les ruines et monuments anciens - ne sont pas la partie la moins intéressante du Journal.

5 L'ouvrage, doté d'un apparat critique discret mais suffisant, est complété par plusieurs annexes: un encart iconographique et l'édition des notes ajoutées par Montalembert à ses carnets. Ces dernières, transcrites et mises en ordre, fournissent des informations tout à la fois sur les condisciples de lycée de l'auteur, sur la chronologie des lettres adressées par lui à certains correspondants, sur l'histoire des progrès de son amour pour Anne de Mérode et sur les instants de bonheur qui l'ont marqué. Aussi, en dépit d'inévitables mais rares petites coquilles orthographiques dans un texte aussi long, espère-t-on prochaine la publication du tome suivant. 